Article

\title{
Integration of the Metabolomic and Transcriptome Analysis Reveals the Remarkable Compounds of G. bicolor Young and Mature Leaves under Different Iron Nutrient Conditions
}

\author{
Zhe Feng ${ }^{1,2}$, Shuyu Ji ${ }^{1,2}$ and Di Cui ${ }^{1,2, *}$ \\ 1 College of Biosystems Engineering and Food Science, Zhejiang University, 866 Yuhangtang Road, \\ Hangzhou 310058, China; 11713010@zju.edu.cn (Z.F.); jishuyujade@zju.edu.cn (S.J.) \\ 2 Key Laboratory of on Site Processing Equipment for Agricultural Products, 866 Yuhangtang Road, \\ Hangzhou 310058, China \\ * Correspondence: dicui@zju.edu.cn; Tel.: +86-159-256-006-17
}

check for updates

Citation: Feng, Z.; Ji, S.; Cui, D. Integration of the Metabolomic and Transcriptome Analysis Reveals the Remarkable Compounds of G. bicolor Young and Mature Leaves under Different Iron Nutrient Conditions. Int. J. Mol. Sci. 2022, 23, 1160 https://doi.org/10.3390/ijms23031160

Academic Editor: Melpo

Christofidou-Solomidou

Received: 18 December 2021

Accepted: 19 January 2022

Published: 21 January 2022

Publisher's Note: MDPI stays neutral with regard to jurisdictional claims in published maps and institutional affiliations.

Copyright: (C) 2022 by the authors. Licensee MDPI, Basel, Switzerland. This article is an open access article distributed under the terms and conditions of the Creative Commons Attribution (CC BY) license (https:// creativecommons.org/licenses/by/ $4.0 /)$.

\begin{abstract}
Gynura bicolor (Roxb. ex Willd.) DC. (G. bicolor) is a functional vegetable rich in iron (Fe) and widely grown in Asia (e.g., Japan and China). Because most Fe in the soil exists in the form of insoluble oxides or hydroxides, it is difficult for plants to obtain Fe from the soil. A comparative metabolomic and transcriptome study was carried out to investigate the effect of Fe deficiency on metabolite synthesis and gene expression in young and mature leaves of G. bicolor. Fe deficiency caused chlorosis and decreased the chlorophyll content in young leaves. The metabolomic results for young leaves showed that l-glutamate and 4-hydroxybutanoic acid lactone significantly increased and decreased, respectively. The transcriptome results showed that the expression levels of genes involved in ferric reduction oxidase 7 and 14-kDa proline-rich protein DC2.15-like were significantly upregulated and downregulated, respectively. However, Fe deficiency had little effect on mature leaves.
\end{abstract}

Keywords: metabolomics; transcriptome; Fe-deficiency stress; G. bicolor; glutamate

\section{Introduction}

Iron $(\mathrm{Fe})$ is the fourth most abundant element in the Earth's crust, but it is usually present in the form of insoluble oxides or hydroxides. Especially in saline and alkaline soils, the solubility of Fe is extremely low [1]. Iron is also an essential element for plants and is involved in many important biological processes, such as nitrogen fixation [2], photosynthesis [3] and respiration [4]. Plants have two different strategies to dissolve and transport Fe (strategy 1: $\mathrm{H}^{+}$-ATPase, $\mathrm{Fe}^{3+}$ reduction, and $\mathrm{Fe}^{2+}$ transport system; strategy 2: synthesis and secretion of mugineic acid). In addition, Fe deficiency affects the synthesis of cytochromes, catalases, peroxidases, and metalloflavoproteins. A phenotype of $\mathrm{Fe}$ deficiency in plants is obvious; chlorosis occurs because of the inhibition of chlorophyll (Chl) synthesis (leaf chloroplasts contain $80 \%$ iron [5]). Interveinal chlorosis first appears in young leaves [5]. Fe deficiency severely affects energy and substance metabolism in plants. Prolonged iron deficiency results in quality deterioration and yield losses of crops. In addition, Fe deficiency in crops can also affect the human intake of Fe, leading to diseases such as iron-deficiency anaemia. Moreover, $\mathrm{Fe}$ is one of the most abundant trace elements in the human body, and its main roles are as follows: (1) it is an important component of haemoglobin and is involved in oxygen transport and storage; (2) it has an impact on the immune system; and (3) it is directly involved in metabolism [6]. Adolescents and menstruating women have a high demand for iron [7]. Fortunately, plants can induce a series of response mechanisms to adapt to Fe-deficiency stress. Roots will secrete a lot of organic acids, phenols and other reducing substances, thus increasing the solubility of external Fe [8,9]. Moreover, some plants regulate the metabolism of butanoate and amino acid to enhance tolerance [10]. 
Gynura bicolor (Roxb. ex Willd.) DC. (G. bicolor) is a functional plant grown in many countries (including China, Japan, Thailand and Myanmar). G. bicolor is well known for its richness in minerals, vitamins, fibre and protein [11]. In particular, its leaves have iron (Fe) levels as high as $3.26 \mu \mathrm{g} / \mathrm{g}$, and its extracts have been shown to promote the bioavailability of Fe in rats [12]. Moreover, in many countries, G. bicolor is used not only as food but also as folk medicine [13]. It has been used customarily as a traditional herbal medicine for dysmenorrhea, iron-deficiency anaemia, and diabetes mellitus, among other conditions [14]. Therefore, an increasing number of plant factories cultivate G. bicolor, and its business value will be further explored in the future.

Plant growth conditions are unsuitable, complex and changeable (e.g., nutrition deficiency, chilling and drought stress). They will evolve a series of resistance mechanisms such as gene expression regulation and metabolic release [15,16]. Most mineral deficiencies affect plant hormone secretion, enzyme activity, reaction oxygen metabolism and photosynthesis. For example, zinc deficiency will significantly influence energy metabolism and protein synthesis [17]. Potassium deficiency will lead to the accumulation of putrescine, particularly in leaves, which can be used as the biomarker metabolite to monitor nutritional needs of plants [18]. To deeply understand plant responses under different growth conditions, high-throughput and efficient multi-omics joint analysis technology has been introduced in the field of plant physiology. An increasing number of researchers are using metabolomics and transcriptomics to elucidate the genetic mechanisms of plant responses to abiotic stress $[19,20]$. Metabolomic analysis can serve as an important supplementary method for transcriptome to maximize the mining of key, hidden information and to validate core data [21].

In this study, metabolomic and transcriptome approaches were used to analyze the young and mature leaves of G. bicolor under Fe deficiency. The biomarkers and key genes of leaves were examined, and the adaptive mechanisms of G. bicolor to Fe deficiency were investigated. An understanding of these mechanisms can serve as a basis for the development of cultivars with Fe-deficiency tolerance.

\section{Results}

\subsection{Phenotypic Analysis of G. bicolor under Fe-Deficiency Stress}

Twenty-four plants were randomly selected for fresh and dry weight determination. Following 21 days of Fe deficiency, there was a significant reduction in both fresh and dry weight of G. bicolor compared to the control group (Figure 1). Fe-deficiency treatment also led to a reduction in leaf length, but the effect on leaf width was not significant $(n=10)$ (Figure 1). The SPAD values of old leaves were not significantly different between the control and test groups during 21 days of treatment (Figure 2). However, the SPAD value of new leaves tended to decrease during the Fe-deficiency treatment, while that of new leaves in the control group increased (Figure 2). Fe-deficiency treatment significantly decreased the SPAD value of the top leaves (length $>3 \mathrm{~cm}$ ) in the control group on Day 21 (Figure 2). Similarly, Chl a and b in new leaves (test group) were only 0.17 and $0.12 \mathrm{mg} / \mathrm{g}$, while those in the control group were 0.51 and $0.28 \mathrm{mg} / \mathrm{g}$, respectively (Figure 2). Fe deficiency slowed the growth of G. bicolor and adversely affected $\mathrm{Chl}$ a and b synthesis in new leaves.

\subsection{Effect of Fe-Deficiency on Element Content of Leaves}

As shown in Table 1, the Fe concentration significantly decreased in new leaves under Fe-deficiency stress, while there was no significant change in old leaves between the two groups. Moreover, the imposition of Fe-deficiency treatment significantly increased the zinc $(\mathrm{Zn})$ content in old and new leaves. The concentration of phosphorus $(\mathrm{P})$ also increased in new leaves. However, there were no significant changes in calcium (Ca) and magnesium $(\mathrm{Mg})$ contents. 


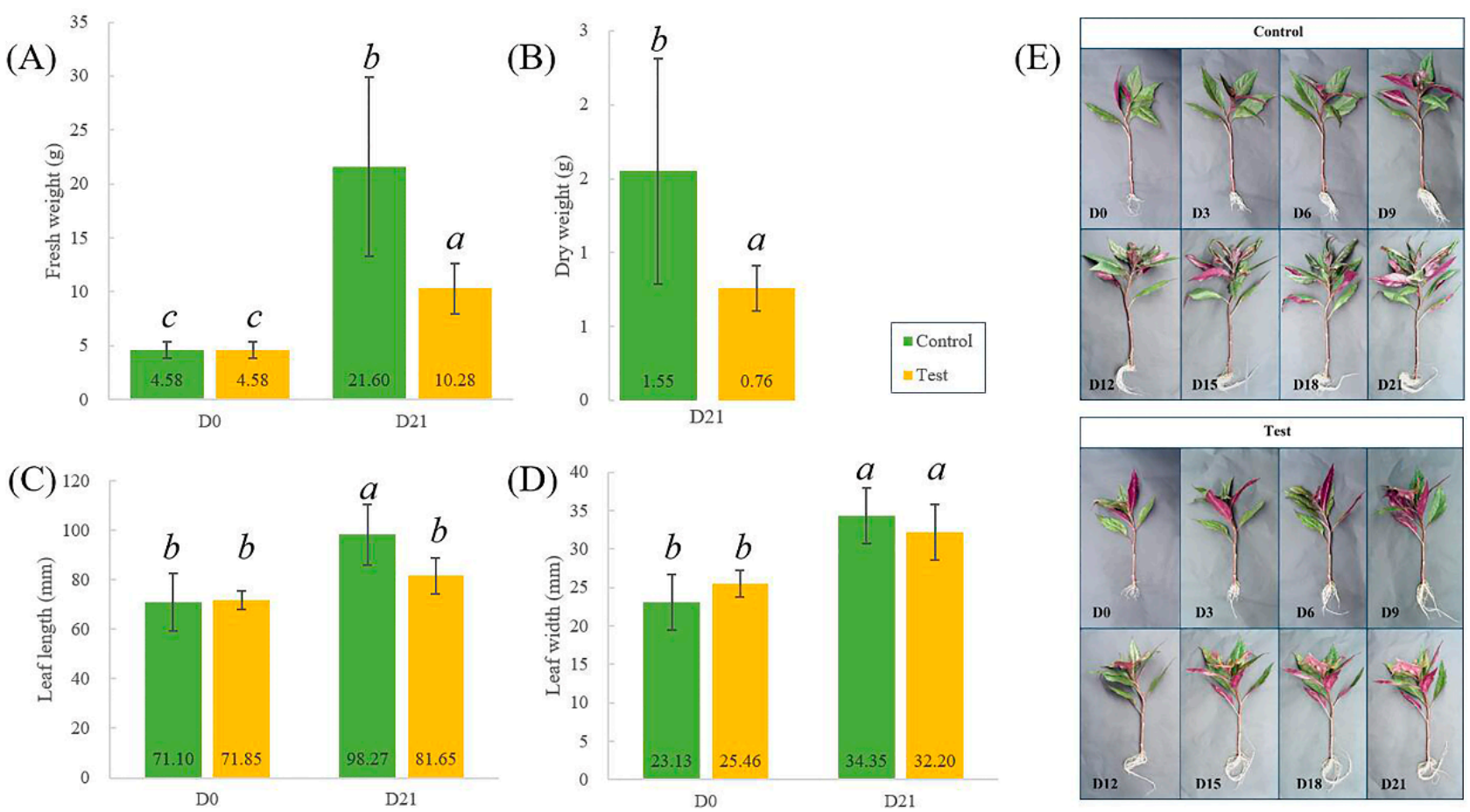

Figure 1. The effect of Fe-deficiency stress on fresh and dry weight $(\mathbf{A}, \mathbf{B})$ and leaf length and width (C,D). Photographs of Gynura bicolor under Fe-deficiency stress (E). Bars indicate standard deviation (SD, $n=24)$. Control = $36.7 \mathrm{mg} / \mathrm{L}$ FeNaEDTA; Test $=0 \mathrm{mg} / \mathrm{L}$ FeNaEDTA. Different letters indicate significant differences, and the same letters indicate nonsignificant differences (ANOVA, $p<0.05$ ). Di refers to the abbreviations of Day $i(i=0,3,6,9,12,15,18$ and 21).

Table 1. The element content of leaves of Gynura bicolor in different Fe treatments.

\begin{tabular}{ccccccc}
\hline \multirow{2}{*}{ Tissue } & Group & \multicolumn{3}{c}{ Element Content (mg/g FW-1) } \\
& & Fe & Ca & Mg & Zn & P \\
\hline \multirow{2}{*}{ New leaf } & Control & $0.04 \pm 0.022$ & $16.25 \pm 2.56$ & $7.57 \pm 0.94$ & $0.06 \pm 0.00$ & $4.94 \pm 0.40$ \\
& Test & $0.02 \pm 0.006^{*}$ & $18.21 \pm 1.81 \mathrm{~ns}$ & $7.49 \pm 0.52 \mathrm{~ns}$ & $0.16 \pm 0.02 * *$ & $6.46 \pm 0.52 * *$ \\
\multirow{2}{*}{ Old leaf } & Control & $0.06 \pm 0.017$ & $11.85 \pm 1.16$ & $5.46 \pm 0.36$ & $0.06 \pm 0.01$ & $4.16 \pm 0.20$ \\
& Test & $0.04 \pm 0.021 \mathrm{~ns}$ & $12.82 \pm 2.62 \mathrm{~ns}$ & $5.52 \pm 1.12 \mathrm{~ns}$ & $0.11 \pm 0.03 * *$ & $4.90 \pm 1.08 \mathrm{~ns}$ \\
\hline
\end{tabular}

Note: The values show mean \pm SD from ten replicates. An independent samples $t$ test was used to calculate $p$ values. ${ }^{*} p<0.05,{ }^{* *} p<0.01, \mathrm{~ns}=$ not significant. Control $=36.7 \mathrm{mg} / \mathrm{L}$ FeNaEDTA; Test $=0 \mathrm{mg} / \mathrm{L}$ FeNaEDTA.2.3. Metabolomics Analysis of G. bicolor Response to Fe Deficiency.

An untargeted metabolomics approach was used to explore the difference in metabolites between the control and test groups. The OPLS-DA results for the new and old leaves using $\mathrm{t}[1] \times \mathrm{t}$ [2] score plots distinguished the test group from the control group (Figure 3). In the positive and negative ion modes, the control and test groups were separated effectively for new leaves (Figure 3). However, there was no significant difference between the control and test groups for old leaves (Figure 3), and the volcano plots of metabolomics in the nTable ew and old leaf samples were shown in Figure S1. Iron is not readily mobile in different parts of the plant, and this is reflected by chlorosis of the youngest leaves but not the older leaves. The classification results for old leaves showed that Fe deficiency had no significant effect on $G$. bicolor in terms of leaf color, but it also did not significantly affect the synthesis of metabolites. 


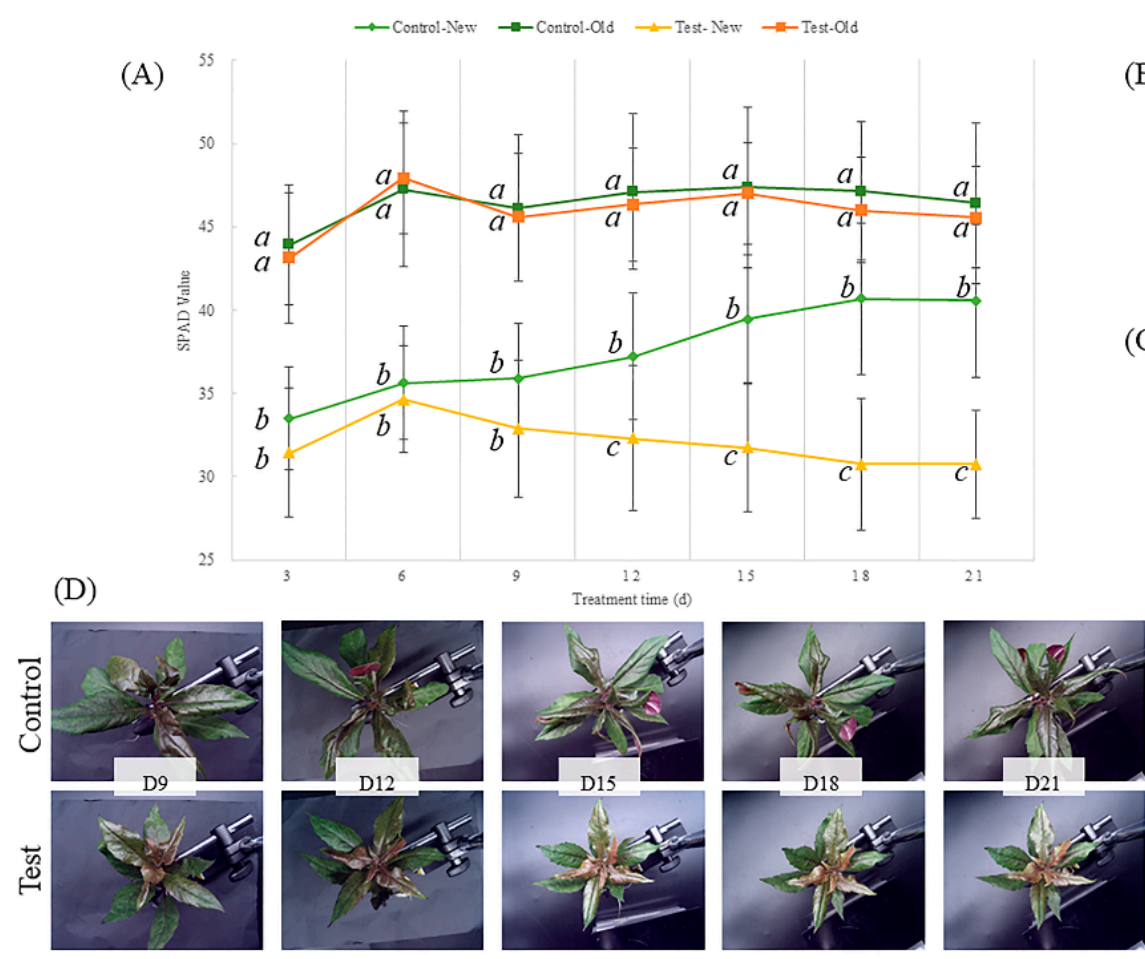

(B)

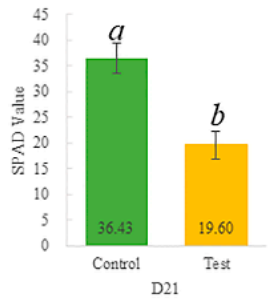

(C)

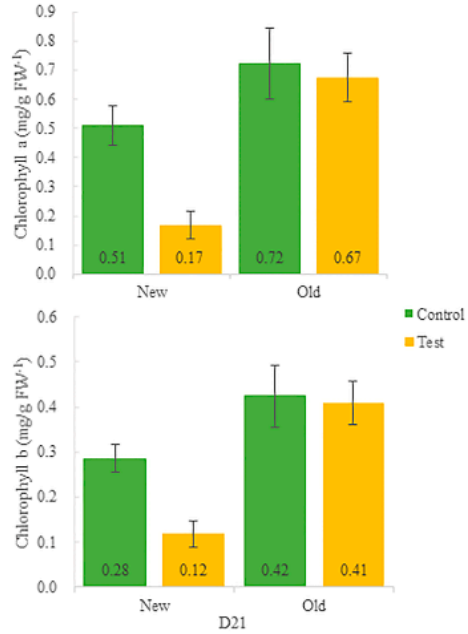

Figure 2. SPAD values of new and old leaves (A) measured in the top leaves (leaf length $>3 \mathrm{~cm}, \mathrm{n}=24$ ) (B). Effect of Fe-deficiency treatment on chlorophyll a and b (C). Photographs of Gynura bicolor under Fe-deficiency stress (D). Leaves that grew during this experiment were defined as new leaves, and leaves that existed before this experiment (leaf length $>5 \mathrm{~cm}$ ) were defined as old leaves. Bars indicate standard deviation (SD). Control $=36.7 \mathrm{mg} / \mathrm{L}$ FeNaEDTA; Test $=0 \mathrm{mg} / \mathrm{L}$ FeNaEDTA. Different letters indicate significant differences, and the same letters indicate nonsignificant differences (ANOVA, $p<0.05)$. Di refers to the abbreviations of Day $i(i=0,3,6,9,12,15,18$ and 21$)$.

The identified compounds in leaf samples were mainly organic acids and derivatives, organic oxygen compounds, lipids and lipid-like molecules. Significant changes in metabolites are shown in Table 2, and the number of decreased metabolites in new leaf samples was higher than that of increased metabolites. The metabolites that increased and decreased the most were l-glutamate (an approximately 12-fold increase) and 4-hydroxybutanoic acid lactone (an approximately 8-fold decrease). In addition, 1-aminocyclopropanecarboxylic acid (ACC) and d-proline increased, while 4-aminobutyric acid, nicotinate, pyridoxal (vitamin B6), choline, adenosine and s-methyl-5'-thioadenosine decreased in new leaves in the test group. In contrast to the results for the new leaf samples, cytidine, 2'-O-methyladenosine and adenosine increased, and adenosine decreased in the old leaf samples. Moreover, the number of the changed metabolites in old leaf samples was less than that in new leaf samples. Correlation network analysis results and the correlation heatmap based on the metabolites found in the new leaves were shown in Figure 3, and these results exhibit the relationships between metabolites in the new leaf samples. L-glutamate, 4-hydroxybutanoic acid lactone and 1-aminocyclopropanecarboxylic acid had the high connectivity and 1glutamate had the highest number of connections.

The changes of leaf metabolites involved in the carbon metabolism were shown in Figure 4. The contents of 1-malic acid, alpha-d-glucose and 3-deoxy-2-keto-6-phosphogluconic acid changed significantly between old and new leaves, while there was no significant difference between the control and test groups of old or new leaves. Moreover, d-glucono1,5-lactone and dihydroxyacetone had significant changes in the old leaves between the test and control groups, while citrate, 1-aspartate, l-glutamate and glyceric acid had significant changes in the new leaves. 

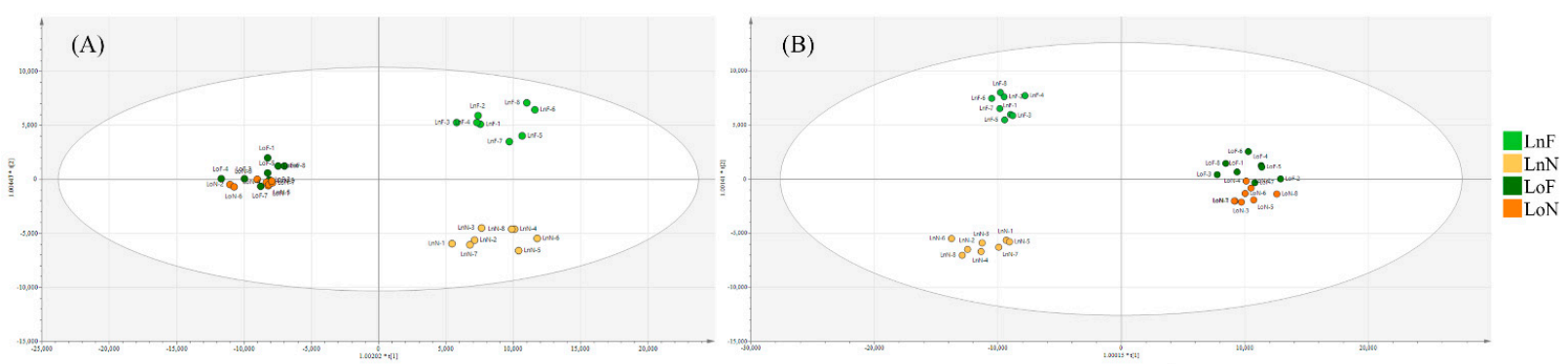

(C)

(D)
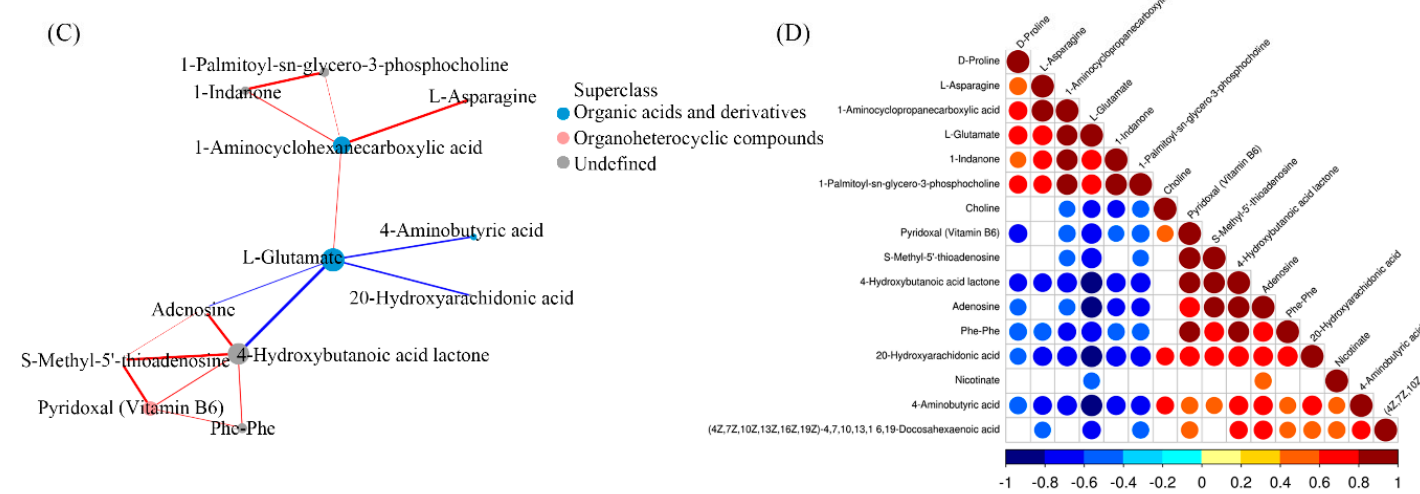

Figure 3. Metabolomics analysis of Gynura bicolor leaves in response to Fe deficiency. Orthogonal partial least squares discriminant analysis (OPLS-DA) score plots in the positive (A) and negative (B) ion modes of G. bicolor leaf samples. (C) Correlation network of metabolites from the new leaves. Node size and color indicate the degree and classification, respectively. Red lines correspond to a positive correlation, and blue lines correspond to a negative correlation. (D) The correlation heatmap was based on the metabolites found in the new leaves. (LoF, the old leaves of the control group; LoN, the old leaves of the test group; LnF, the new leaves of the control group; $\mathrm{LnN}$, the new leaves of the test group).

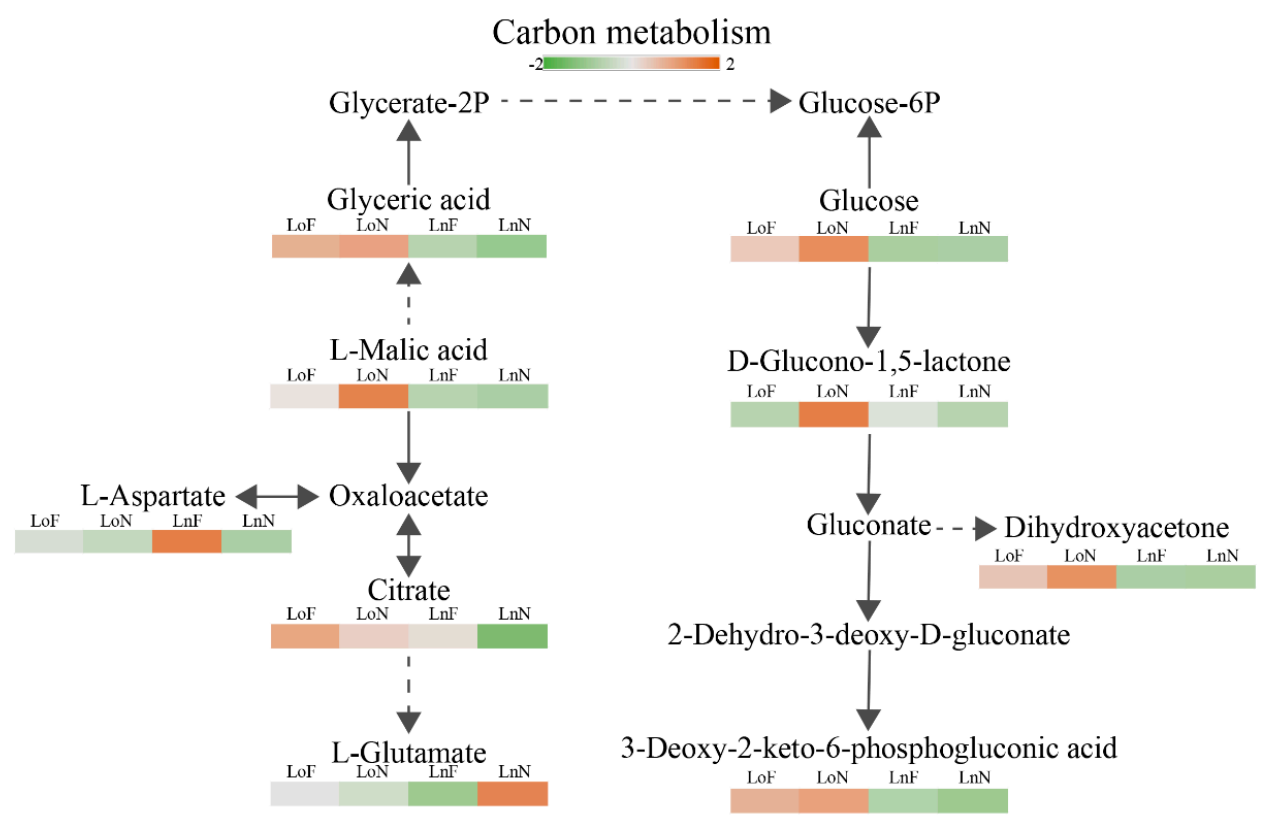

Figure 4. The carbon metabolism pathway shows the changes in Gynura bicolor leaves in response to Fe deficiency. Heatmaps show the different accumulations of metabolites. (LoF, the old leaves of the control group; LoN, the old leaves of the test group; LnF, the new leaves of the control group; $\mathrm{LnN}$, the new leaves of the test group.). 
Table 2. Characteristics of differential metabolites of Gynura bicolor in different Fe treatments. $(\mathrm{n}=8)$.

\begin{tabular}{|c|c|c|c|c|c|c|c|}
\hline Iron Mode & Tissue & Metabolites & VIP & Fold Change & $p$-Value & $m / z$ & RT(s) \\
\hline \multirow{18}{*}{ Positive } & \multirow{14}{*}{ New leaf } & 4-Hydroxybutanoic acid lactone & 1.57 & 0.11 & 0.0000 & 87.0432 & 402.47 \\
\hline & & Phe-Phe & 1.00 & 0.23 & 0.0000 & 313.1533 & 154.17 \\
\hline & & Pyridoxal (Vitamin B6) & 2.10 & 0.36 & 0.0000 & 168.0639 & 95.96 \\
\hline & & 4-Aminobutyric acid & 2.00 & 0.37 & 0.0000 & 104.0705 & 368.79 \\
\hline & & S-Methyl-5'-thioadenosine & 3.65 & 0.38 & 0.0000 & 298.0953 & 98.92 \\
\hline & & Adenosine & 13.85 & 0.47 & 0.0001 & 268.1026 & 168.71 \\
\hline & & Nicotinate & 1.04 & 0.56 & 0.0415 & 124.0373 & 215.08 \\
\hline & & Choline & 1.58 & 0.59 & 0.0458 & 104.1059 & 390.71 \\
\hline & & $\begin{array}{l}\text { 4,7,10,13,16,19-Docosahexaenoic } \\
\text { acid }\end{array}$ & 1.41 & 0.66 & 0.0137 & 328.2463 & 68.75 \\
\hline & & D-Proline & 1.57 & 1.92 & 0.0361 & 116.0693 & 308.51 \\
\hline & & L-Asparagine & 1.86 & 3.30 & 0.0001 & 133.0592 & 396.60 \\
\hline & & 1-Indanone & 1.24 & 3.58 & 0.0035 & 193.0843 & 32.62 \\
\hline & & 1-Aminocyclopropanecarboxylic acid & 1.14 & 3.62 & 0.0002 & 84.0433 & 376.98 \\
\hline & & $\begin{array}{l}\text { 1-Palmitoyl-sn-glycero-3- } \\
\text { phosphocholine }\end{array}$ & 1.02 & 7.70 & 0.0085 & 496.3372 & 188.96 \\
\hline & \multirow{4}{*}{ Old leaf } & Adenosine & 4.36 & 0.46 & 0.0025 & 268.1026 & 168.71 \\
\hline & & Cytidine & 2.74 & 2.10 & 0.0074 & 244.0922 & 236.66 \\
\hline & & 2'-O-methyladenosine & 1.46 & 1.48 & 0.0154 & 282.1183 & 130.78 \\
\hline & & Uracil & 1.02 & 1.22 & 0.0226 & 113.0331 & 162.04 \\
\hline \multirow{5}{*}{ Negative } & \multirow{3}{*}{ New leaf } & Salicylic acid & 1.00 & 2.76 & 0.0001 & 137.0237 & 78.27 \\
\hline & & Citrate & 3.58 & 0.06 & 0.0004 & 191.0203 & 470.66 \\
\hline & & L-Glutamine & 1.08 & 3.71 & 0.0009 & 145.0609 & 386.60 \\
\hline & \multirow[b]{2}{*}{ Old leaf } & D-Lyxose & 1.66 & 1.51 & 0.0072 & 149.0445 & 153.51 \\
\hline & & D-Glucono-1,5-lactone & 1.28 & 1.94 & 0.0185 & 177.0394 & 158.68 \\
\hline
\end{tabular}




\subsection{Transcriptome Analysis of the G. bicolor Response to Fe Deficiency}

The GO (Figure 5B) and KEGG (Figure 6C,D) enrichment analyses of the G. bicolor leaf response to Fe deficiency were carried out to find the key genes. Volcano plots of expressed genes in the new leaf samples were shown in Figure S2. There were 1436 and 285 differentially expressed genes (DEGs) in the new and old leaf samples, respectively, and 60 identical DEGs (Figure 6), which indicated that Fe deficiency had little effect on the transcription process in old leaves. Among DEGs in new leaf samples, 787 DEGs were upregulated and 649 DEGs were downregulated. Moreover, one of the most upregulated genes was related to ferric reduction oxidase 7 (FRO7, approximately 64-fold), while one of the most downregulated genes was related to 14-kDa proline-rich protein DC2.15-like (PRPDC2.15, approximately 16-fold). FROs have diverse roles in Fe distribution and uptake within plants, and FRO7 is responsible for Fe delivery to chloroplasts [22-24]. PRPDC2.15 encodes cell wall structural proteins, and Fan et al. (2014) [25] found that it was downregulated in Arabidopsis under aluminum stress. And the expression level of ethylene-responsive transcription factor (ERF) significantly decreased (more than 64-fold). Dai et al., (2018) [26] found that ERF was downregulated in peanuts under Fe-deficiency stress. In Figure 5A, most of the genes were upregulated in test group of the new leaves. Among these, AP2 (APETALA2) was downregulated in the test group (new leaves), which is widely involved in many biological processes such as growth and development and stress response. But HLH/bHLH (bHLH38, more than 200-fold; bHLH62) transcription regulators were upregulated in test group. The expression of bHLH aided the regulation of Fe-deficiency in plants [27]. In Figure 5B, expression of NAM, bZIP, and HLH transcription factors (TRs) were upregulated. Some AP2 TRs were upregulated and some downregulated. AP2, bHLH, NAC and bZIP TRs are all associated with terpenoid metabolism. They are a multigene family ubiquitous in eukaryotes, which can effectively regulate the biosynthesis of plant secondary metabolites. Overexpressed bZIP can significantly improve the ability of plants to resist abiotic stress [28,29]. In the case of the KEGG pathways of DEGs (Figure 6), the pathways related to brassinosteroid biosynthesis, limonene and pinene degradation, thiamine metabolism, chloroalkane, chloroalkene degradation, and fatty acid degradation were significantly upregulated, while the pathways related to phenylalanine, tyrosine and tryptophan biosynthesis, stilbenoid, diarylheptanoid and gingerol biosynthesis, flavonoid biosynthesis, flavone and flavonol biosynthesis, and anthocyanin biosynthesis were significantly downregulated.

\subsection{The Correlation between the Metabolome and Transcriptome}

As shown in Figures 3 and 4, metabolomic and transcriptome data indicated that Fe deficiency had less effect on old leaves. The expression levels of genes involved in glutathione S-transferase (GST) and the content of l-glutamate increased in new leaf samples (Figure 4E). GSTs play an important role in enhancing plant tolerance of the environment and resistance to injury [30], and a high ratio of GSTs is important for ROS scavenging in plants. Zeng et al. (2015) [31] found that the proteins related to GSTs in the sensitive barley genotype dramatically decreased under potassium deficiency stress, and Yang et al., (2019) [32] found that overexpression of GSTs from Populus increased the salt and drought tolerance of Arabidopsis. In addition, glutamate is a core amino acid in plants. It not only participates in the synthesis of various amino acids but also regulates important physiological metabolic processes [33]. Gynura bicolor might improve tolerance to Fe deficiency by increasing the expression of GSTs. 


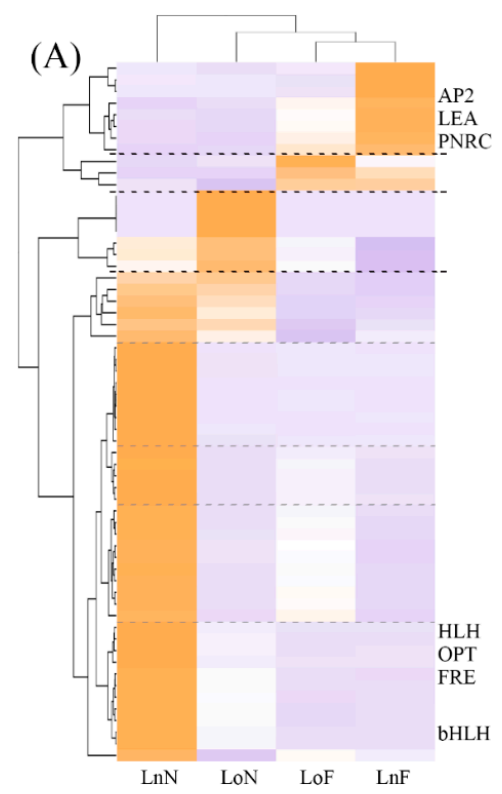

(B)
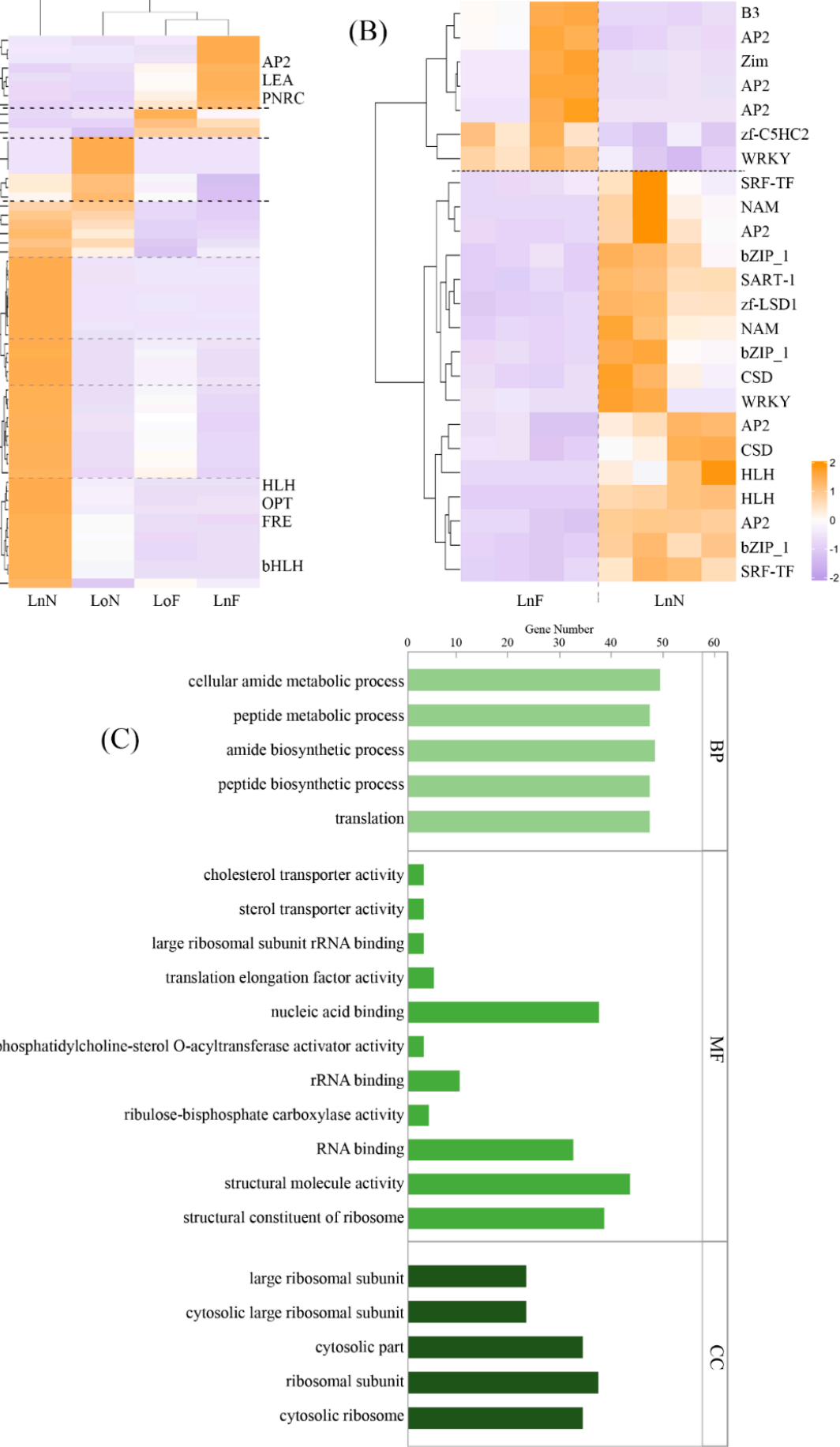

Figure 5. Transcriptome analysis of Gynura bicolor leaves in response to Fe deficiency. Heatmap showed the different accumulations of genes in both old and new leaf samples (A). Heatmap showed the key different accumulations of genes in new leaf samples (B). GO enrichment analysis of the differentially expressed genes in the new leaf samples (C). (LoF, the old leaves of the control group; $\mathrm{LoN}$, the old leaves of the test group; LnF, the new leaves of the control group; LnN, the new leaves of the test group). 
(A)

Old leaf: Fe-deficiency vs control
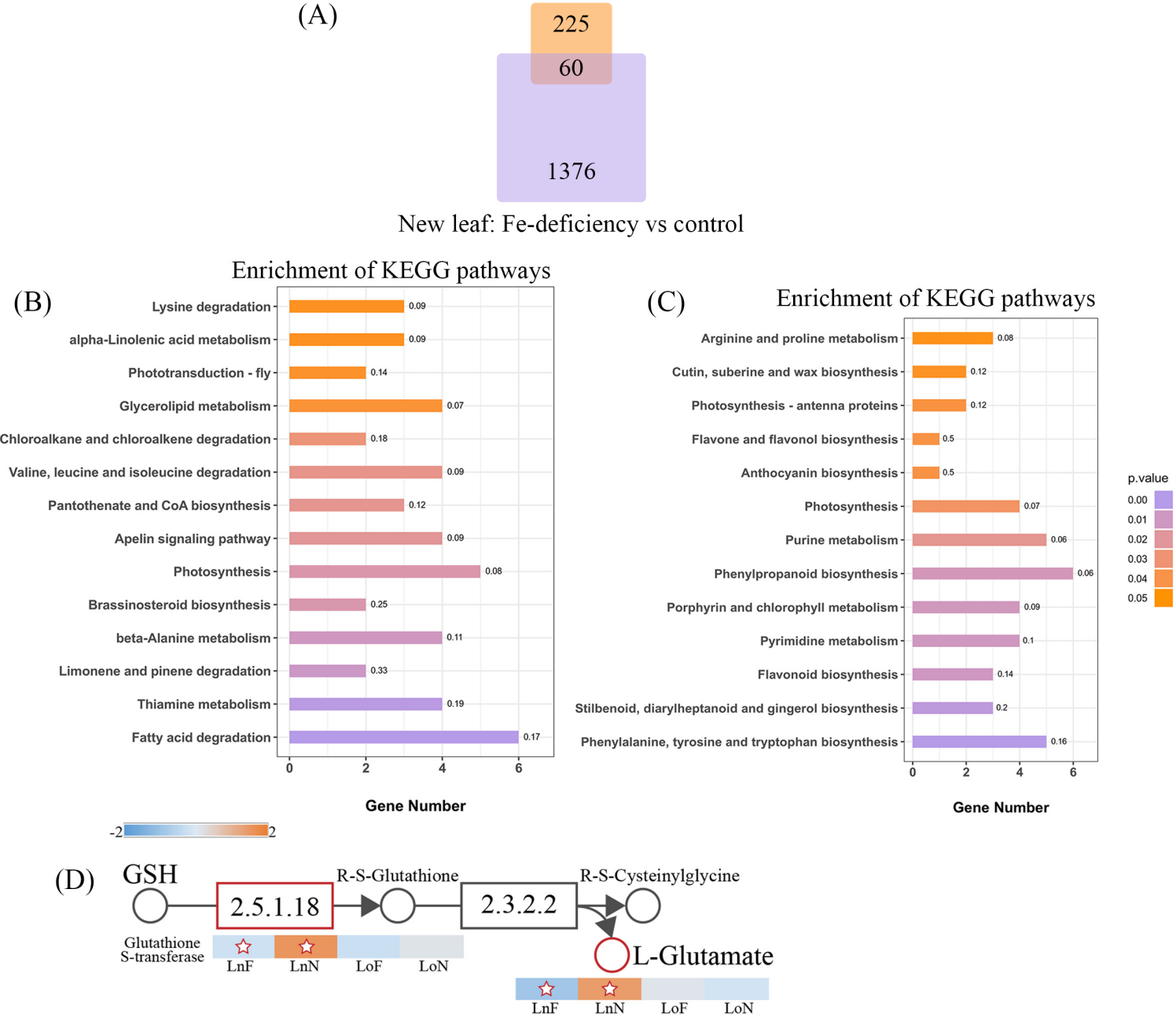

(E)

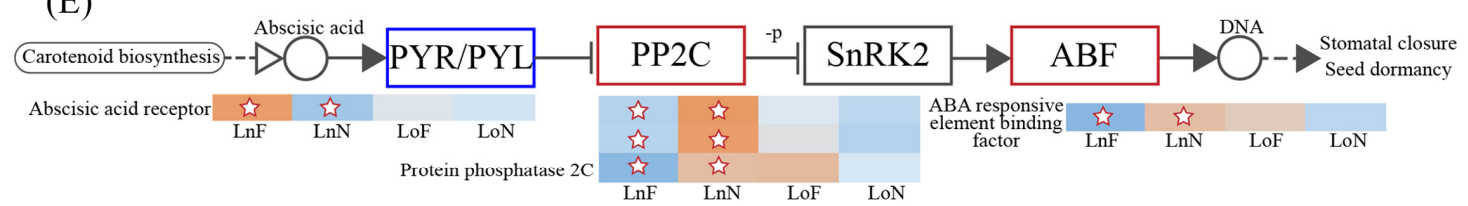

Salicylic acid

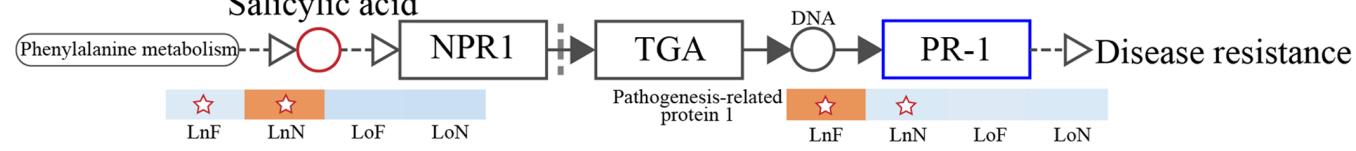

Figure 6. Transcriptome and metabolomic analysis of Gynura bicolor leaves in response to Fe deficiency. (A) The number of differentially expressed genes (DEGs) in the new and old leaf samples. $(\mathbf{B}, \mathbf{C})$ KEGG pathway enrichment analysis of the DEGs in the new leaf samples ((B): upregulated; (C): downregulated). (D,E) Pathway analysis of metabolites and genes in leaves of G. bicolor under Fe-deficiency conditions. Different colors indicate metabolite and gene accumulation levels (red: upregulated, blue: downregulated). Heatmaps showed the different accumulations of metabolites or genes, and metabolites or genes with significant differences ( $p$-value $>0.05$ ) between the control and test groups are denoted by stars. ((D): glutathione metabolism; (E): plant hormone signal transduction.).

The expression levels of genes involved in protein phosphatase $2 \mathrm{C}$ (PP2C) and abscisic acid (ABA)-responsive element binding factor $(A B F)$ increased, while those in the $A B A$ receptor PYR/PYL family decreased in new leaf samples (Figure $4 \mathrm{~F}$ ). ABF, a regulatory 
factor, plays an important role in plant resistance to abiotic stress. Wang et al., (2019) [34] found that ABF played a role in cabbage under calcium deficiency stress, and Dossa et al. (2017) [35] found that ABF was upregulated in sesame under drought stress. In addition, PP2C, a constitutive protein phosphatase with multiple functions, is widely involved in various protein kinase signaling pathways caused by stress as a negative regulator in organisms [36]. PP2Cs are involved in potassium deficiency-triggered signaling [37]. Tiwari et al., (2020) [38] found that protein phosphatase-2c was highly upregulated in potato roots under nitrogen stress. ABA receptors are an important signaling molecule in the ABA signaling pathway in plants, and PYR/PYL proteins can inhibit PP2C activity [39]. In this study, the expression levels of genes involved in $\mathrm{ABF}$ were upregulated, indicating that $G$. bicolor might have the ability to fight Fe-deficiency stress.

\section{Discussion}

\subsection{Impacts of Fe Deficiency on Metabolism}

Elemental analysis indicated that Fe-deficiency treatment affected new leaves more than old leaves and that Fe was an immobile nutrient [5]. In addition, Zn might play a key role in resistance to Fe-deficiency stress. Similarly, Arrivault et al., (2006) [40] found that Fe deficiency enhanced the accumulation of $\mathrm{Zn}$ in the aboveground organs of Arabidopsis. The influx rate for other metal ions (e.g., $\mathrm{Zn}^{2+}, \mathrm{Mn}^{2+}$ and $\mathrm{Cd}^{2+}$ ) will increase when plants are subjected to Fe-deficiency stress [41].

Figure 3 showed that Fe deficiency mainly affected the synthesis of 1-glutamate, citrate, 1-aspartate and glyceric acid in the carbon metabolism pathway. The metabolomic results indicated that l-glutamate was the "hub" and played the key role in the network. Glutamate was shown to be involved in the synthesis of a variety of proteins and amino acids related to plant stress resistance. Under stresses, glutamate was metabolized to $\gamma$-aminobutyric acid (GABA), which resulted in the regulation of $\mathrm{pH}$ balance and redox level [42]. However, the metabolomic results showed that the contents of aminobutyric acid and 4-hydroxybutanoic acid lactone decreased in new leaf samples, while the content of glutamine increased. It indicated that the glutamic acid decarboxylase activity might be inhibited. The polyamine degradation pathway was another pathway to synthesize GABA, which might be restricted. Moreover, ACC is a direct precursor of ethylene biosynthesis, and ethylene is an important plant hormone. In this study, the contents of ACC and SA significantly increased, but there was no change in ethylene content. The results proved that SA (a major plant hormone) accumulated due to Fe deficiency and involved in the regulation of defense response. The accumulation of endogenous SA activated Fe translocation via the transcriptional regulation, mediated by bHLH38 (upregulated in this study), of the downstream Fe gene [43]. In summary, Gynura bicolor might prefer to stimulate systemic acquired resistance by releasing SA.

The results also showed that the contents of citrate, l-aspartate and glyceric acid decreased in the test group. It agreed with the findings about other abiotic stresses. UrbanczykWochniak \& Fernie (2005) [44] found that citrate and aspartate decreased in tomato leaves under nitrate stress and nitrogen deficiency, respectively. And, L. Liu \& Lin (2020) [45] also found that citrate decreased in Sargassum fusiform leaves under heat stress. However, plant roots synthesize more citrate to cope with the lack of mineral nutrients [46], which might lead to the decline in citrate in leaves. Roots absorb Fe by citrate and Fe complexation, and Fe-citrate is distributed to the mature leaves through transpiration [47]. The photosynthesis and transpiration rate were weakened by Fe deficiency, which might lead to the decline in citrate and some organic acid by influencing the leaf energy metabolism and the tricarboxylic acid cycle.

\subsection{Impacts of Fe Deficiency on Transcriptome}

Gynura bicolor might improve tolerance to Fe deficiency by increasing the expression of GSTs. And, the results of transcriptome analysis showed that bHLH TRs might play a key role in Fe-deficiency stress, and the expression of bHLH TRs in new leaves was significantly 
higher than that in old leaves. What's more, the effect of Fe-deficiency on transcription of new leaves was greater than that of old leaves. The decline in the expression of ZIP-related TRs in new leaf samples might lead to the drop in $\mathrm{Zn}$ content. The expression level of genes involved in pathogenesis-related protein 1 (PR-1) decreased, and PR-1 has biological functions associated with defense against biotic stresses [48]. In this study, SA content increased, but the expression of PR-1 was downregulated, indicating that Fe deficiency would weaken the function in resistance to pathogen attack. Moreover, the expression of bHLH and FRO was upregulated, which indicated that the positive regulatory network of Fe-deficiency-centered FIT (HLH29) transcription regulator was activated [49]. FIT overexpression alone does not enhance the iron deficiency response, but co-expression with bHLH activates iron uptake genes. Co-overexpression of FIT and bHLH38 can activate Fe uptake genes to improve Fe deficiency tolerance. The transcriptome results showed that Gynura bicolor could fight against Fe-deficiency stress.

\section{Materials and Methods}

\subsection{Plant Materials}

In this experiment, cuttings were used to propagate G. bicolor seedlings from Wuhan Happy Farm Gardening Co., Ltd. Tender stems (similar in length and quality) were selected from healthy parental plants with the same growth as cuttings. The cuttings were cultivated in perlite for two weeks and then moved to hydroponic tanks in an artificial climate chamber $\left(16 \mathrm{~h}\right.$ light at $25 \pm 1{ }^{\circ} \mathrm{C}, 8 \mathrm{~h}$ dark at $19 \pm 1{ }^{\circ} \mathrm{C}, 70 \%$ relative humidity, $300 \mu \mathrm{mol} \mathrm{m}{ }^{-2} \mathrm{~s}^{-1}$ photon flux density). One hundred and sixty-eight plants were randomly and equally divided into two groups and grown for 21 days in intermittently aerated nutrient solution. Fe-sufficient plants (control group) were grown in normal nutrient solution (consisting of $945 \mathrm{mg} / \mathrm{L} \mathrm{Ca}\left(\mathrm{NO}_{3}\right)_{2} \cdot 4 \mathrm{H}_{2} \mathrm{O}, 506 \mathrm{mg} / \mathrm{L} \mathrm{KNO}_{3}, 80 \mathrm{mg} / \mathrm{L} \mathrm{NH}_{4} \mathrm{NO}_{3}, 136 \mathrm{mg} / \mathrm{L}$ $\mathrm{KH}_{2} \mathrm{PO}_{4}, 241 \mathrm{mg} / \mathrm{L} \mathrm{MgSO}_{4}, 36.7 \mathrm{mg} / \mathrm{L}$ FeNaEDTA, $0.83 \mathrm{mg} / \mathrm{L} \mathrm{KI}, 6.2 \mathrm{mg} / \mathrm{L} \mathrm{H}_{3} \mathrm{BO}_{3}$, $16.9 \mathrm{mg} / \mathrm{L} \mathrm{MnSO}_{4} \cdot \mathrm{H}_{2} \mathrm{O}, 8.6 \mathrm{mg} / \mathrm{L} \mathrm{ZnSO}_{4} \cdot 7 \mathrm{H}_{2} \mathrm{O}, 0.25 \mathrm{mg} / \mathrm{L} \mathrm{Na}_{2} \mathrm{MoO}_{4} \cdot 2 \mathrm{H}_{2} \mathrm{O}, 0.025 \mathrm{mg} / \mathrm{L}$ $\mathrm{CuSO}_{4} \cdot 5 \mathrm{H}_{2} \mathrm{O}$, and $0.025 \mathrm{mg} / \mathrm{L} \mathrm{CoCl} \cdot 6 \mathrm{H}_{2} \mathrm{O}$ ) and Fe-deficient plants (test group) were grown under iron-deficient conditions (normal nutrient solution without FeNaEDTA). The first pair of leaves from top to bottom and the first pair from bottom to top were marked (leaf length $>3 \mathrm{~cm}$ ). On Day 0 and Day 21, fresh weight $(\mathrm{FW})$, leaf length and leaf width were recorded. SPAD (Konica Minolta, SPAD-502 Plus, Tokyo, Japan) readings were made every two days. Leaves that grew during this experiment (young leaves) were defined as new leaves, and those that existed before this experiment (mature leaves, leaf length $>5 \mathrm{~cm}$ ) were defined as old leaves. The plants were placed in a drying oven at $105^{\circ} \mathrm{C}$ for $15 \mathrm{~min}$, and then the temperature was adjusted to $70{ }^{\circ} \mathrm{C}$ until a constant weight was reached. The dry weight (DW) was then measured. Microwave digestion and inductively coupled plasma-optical emission spectrometry (ICP-OSE) was used for trace element analysis (Fe, $\mathrm{Mg}, \mathrm{Zn}, \mathrm{P}$ and $\mathrm{Ca}$ ) in plants. Forty-eight plants were randomly selected for metabolomics analysis (twenty-four of these were used for transcriptome analysis). These samples were powdered in liquid nitrogen and stored at $-80^{\circ} \mathrm{C}$.

\subsection{Determination of Chlorophyll Content}

Leaf samples were collected on Day 21. Samples were weighed to $1 \mathrm{~g}$ and then extracted with $80 \%$ acetone solution for $30 \mathrm{~min}$ in a dark environment. Under lightshielding conditions, the extract was filtered, and the absorbance was measured using a UV-Visible spectrophotometer (Thermo Scientific, Evolution 220). Chlorophyll a and b contents (mg/g) were calculated using the following formula [50,51]:

$$
\begin{aligned}
& \mathrm{C}_{\mathrm{a}}=\left(12.71 \times \mathrm{A}_{663}-2.59 \times \mathrm{A}_{645}\right) \times \mathrm{V} / \mathrm{W} \\
& \mathrm{C}_{\mathrm{b}}=\left(22.88 \times \mathrm{A}_{645}-4.67 \times \mathrm{A}_{663}\right) \times \mathrm{V} / \mathrm{W}
\end{aligned}
$$


where $C_{a}$ and $C_{b}$ are the amounts of chlorophyll a and b, respectively. A663 and A645 were the absorbance values at 663 and $645 \mathrm{~nm}$, respectively. V was the volume of the extract, and $\mathrm{W}$ was the FW of the sample.

\subsection{Transcriptome Data Acquisition}

The leaves of each plant were removed from the same position. The first pair of new leaves (leave length $>3 \mathrm{~cm}$ ) on the top and the last pair of old leaves at the bottom were removed from each plant (Figure S3). RIzol $^{\circledR}$ Reagent was used to extract total RNA from the leaves according to the manufacturer's instructions (Magen). A Nanodrop ND2000 system (Thermo Scientific, CA, USA) was used to detect the A260/A280 absorbance ratio of RNA samples. The overall quality of the samples was determined by agarose gel electrophoresis. An ABclonal mRNA-seq Lib Prep Kit (ABclonal, Shanghai, China) was used to prepare the paired-end libraries. The fragmentation of mRNA (purified from $1 \mu \mathrm{g}$ total RNA) was carried out in ABclonal First Strand Synthesis Reaction Buffer. Subsequently, first- and second-strand cDNAs were synthesized (mRNA fragments as templates used random hexamer primers and RNase H, DNA polymerase I, dNTPs and buffer) and were used for PCR amplification. An Illumina NovaSeq 6000 instrument was used for sequencing.

\subsection{Metabolomics Data Acquisition}

Frozen samples were mixed with methanol/acetonitrile/aqueous solution $(2: 2: 1, V / V)$. Quality control (QC) samples (mixing $10 \mu \mathrm{L}$ of each sample) were prepared to ensure the reliability of instrument analysis. An ultra-performance liquid chromatography system (1290 Infinity LC, Agilent Technologies) coupled to quardruple time-of-flight (AB Sciex TripleTOF 6600) was used for metabolomics analysis. Samples were analyzed by HILIC separation (column temperature: $25^{\circ} \mathrm{C}$, flow rate: $0.3 \mathrm{~mL} / \mathrm{min}$ ). The mobile phase contained Phase A ( $25 \mathrm{mM}$ ammonium acetate and $25 \mathrm{mM}$ ammonium hydroxide in water) and Phase B (acetonitrile). Chromatographic and ESI source conditions are described in the Supplemental Material.

\subsection{Data Analysis}

Statistical analyses were performed using SPSS Statistics 19 software (IBM, Chicago, USA). Data were shown as averages. According to the results of the variance homogeneity test, a one-way analysis of variance (ANOVA) and independent samples t-test were used to detect differences. A probability $(p)$ value of $<0.05$ was considered statistically significant. Orthogonal partial least squares discriminant analysis (OPLS-DA) was used to differentiate the leaf samples by SIMCA 13.0 software (Umetric, Umea, Sweden). The variable importance for the projection (VIP) obtained from the OPLS-DA model can be used to measure the strength of the expression pattern of each metabolite on the classification of each group of samples. In this experiment, VIP $>1$ and a $p$-value $<0.05$ were used as the screening criteria for significantly different metabolites. The differentially expressed genes were adopted by KEGG enrichment analysis.

\section{Conclusions}

In this study, the molecular mechanism of G. bicolor response to Fe deficiency was investigated by combined metabolomics and transcriptome analyses. The effects of Fedeficiency stress on the new and old leaves of G. bicolor were also studied. Fe deficiency can lead to the yellowing of young leaves of plants but has no significant effect on the color of mature leaves, findings that were verified in this study. In addition, the effect of Fe deficiency on metabolism and transcription in mature leaves was less than that in young leaves. Our results indicate that Fe deficiency mainly influenced glutathione metabolism and plant hormone signal transduction in young leaves, which suggests that these pathways play a key role in the response to Fe-deficiency stress in G. bicolor. Furthermore, Fe deficiency resulted in significant downregulation of the pathways related to flavonoid biosynthesis, 
flavone and flavonol biosynthesis, and anthocyanin biosynthesis, which might lead to a decrease in the nutritional value of G. bicolor. Moreover, G. bicolor showed active resistance to Fe-deficiency stress; its protein interaction relationships can be further explored in future research.

Supplementary Materials: The following supporting information can be downloaded at: https: //www.mdpi.com/article/10.3390/ijms23031160/s1.

Author Contributions: Z.F.: conceptualization; Z.F.: data curation; Z.F.: formal analysis; Z.F.: writing-original draft; Z.F. and S.J. were involved in the identification of DEGs; D.C.: writing-review \& editing. All authors have read and agreed to the published version of the manuscript.

Funding: This research was funded by the National Natural Science Foundation of China (Grant No. 31571764) and the Zhejiang Province Welfare Technology Applied Research Project (LGN20C130006).

Institutional Review Board Statement: This study did not involve humans or animals.

Informed Consent Statement: Informed consent was obtained from all subjects involved in the study.

Data Availability Statement: The data presented in this study are available on request from the corresponding author. The data are not publicly available due to privacy.

Acknowledgments: The authors gratefully acknowledge the support of this program by the National Natural Science Foundation of China (Grant No. 31571764) and the Zhejiang Province Welfare Technology Applied Research Project (LGN20C130006).

Conflicts of Interest: The authors declare no conflict of interest.

\section{References}

1. Cohen, C.K.; Fox, T.C.; Garvin, D.F.; Kochian, L.V. The Role of Iron-Deficiency Stress Responses in Stimulating Heavy-Metal Transport in Plants. Plant Physiol. 1998, 116, 1063-1072. [CrossRef] [PubMed]

2. Rotaru, V.; Sinclair, T.R. Interactive influence of phosphorus and iron on nitrogen fixation by soybean. Environ. Exp. Bot. 2009, 66, 94-99. [CrossRef]

3. Wang, Y.; Hu, Y.; Zhu, Y.; Baloch, A.W.; Jia, X.; Guo, A. Transcriptional and physiological analyses of short-term iron deficiency response in apple seedlings provide insight into the regulation involved in photosynthesis. BMC Genom. 2018, 19, 461. [CrossRef]

4. Zhang, X.; Zhang, D.; Sun, W.; Wang, T. The Adaptive Mechanism of Plants to Iron Deficiency via Iron Uptake, Transport, and Homeostasis. Int. J. Mol. Sci. 2019, 20, 2424. [CrossRef] [PubMed]

5. Kathpalia, R.; Bhatla, S.C. Plant Mineral Nutrition. In Plant Physiology, Development and Metabolism; Bhatla, S.C., Lal, M.A., Eds.; Springer: Singapore, 2018; pp. 37-81. ISBN 9789811320231.

6. Briguglio, M.; Hrelia, S.; Malaguti, M.; Lombardi, G.; Riso, P.; Porrini, M.; Perazzo, P.; Banfi, G. The Central Role of Iron in Human Nutrition: From Folk to Contemporary Medicine. Nutrients 2020, 12, 1761. [CrossRef]

7. Abbaspour, N.; Hurrell, R.; Kelishadi, R. Review on iron and its importance for human health. J. Res. Med. Sci. 2014, 19, 164-174.

8. Li, J.; Cao, X.; Jia, X.; Liu, L.; Cao, H.; Qin, W.; Li, M. Iron Deficiency Leads to Chlorosis through Impacting Chlorophyll Synthesis and Nitrogen Metabolism in Areca catechu L. Front. Plant Sci. 2021, 12, 710093. [CrossRef]

9. Kour, J.; Kohli, S.K.; Khanna, K.; Bakshi, P.; Sharma, P.; Singh, A.D.; Ibrahim, M.; Devi, K.; Sharma, N.; Ohri, P.; et al. Brassinosteroid Signaling, Crosstalk and, Physiological Functions in Plants under Heavy Metal Stress. Front. Plant Sci. 2021, 12, 608061. [CrossRef]

10. Zhang, X.; Jia, X.; Zhang, R.; Zhu, Z.; Liu, B.; Gao, L.; Wang, Y. Metabolic analysis in Malus halliana leaves in response to iron deficiency. Sci. Hortic. 2019, 258, 108792. [CrossRef]

11. Qiu, X.-L.; Guo, Y.-X.; Zhang, Q.-F. Chemical profile and antioxidant activity of Gynura bicolor DC. ethanolic extract. Int. J. Food Prop. 2018, 21, 407-415. [CrossRef]

12. Wu, C.; Chang, W.; Lu, C.; Chang, Y.; Wang, J.; Hsieh, S. Effects of extracts from Gynura bicolor (Roxb. \& Willd.) DC. on iron bioavailability in rats. J. Food Drug Anal. 2015, 23, 425-432. [CrossRef]

13. Zhou, X.; Zhou, M.; Liu, Y.; Ye, Q.; Gu, J.; Luo, G. Isolation and Identification of Antioxidant Compounds from Gynura Bicolor Stems and Leaves. Int. J. Food Prop. 2016, 19, 233-241. [CrossRef]

14. ShangQuan, R.; Yue, Y.; JianHong, W.; Di, R. Distribution of mineral elements in Gynura bicolor D. C. and its correlation with soil mineral elements. Med. Plant. 2010, 1, 5-7.

15. Kubes, J.; Skalicky, M.; Tumova, L.; Martin, J.; Hejnak, V.; Martinkova, J. Vanadium elicitation of Trifolium pratense L. cell culture and possible pathways of produced isoflavones transport across the plasma membrane. Plant Cell Rep. 2019, 38, 657-671. [CrossRef] [PubMed]

16. Chu, Q.; Sha, Z.; Maruyama, H.; Yang, L.; Pan, G.; Xue, L.; Watanabe, T. Metabolic reprogramming in nodules, roots, and leaves of symbiotic soybean in response to iron deficiency. Plant. Cell Environ. 2019, 42, 3027-3043. [CrossRef] [PubMed] 
17. Bouain, N.; Krouk, G.; Lacombe, B.; Rouached, H. Getting to the Root of Plant Mineral Nutrition: Combinatorial Nutrient Stresses Reveal Emergent Properties. Trends Plant Sci. 2019, 24, 542-552. [CrossRef]

18. Cui, J.; Pottosin, I.; Lamade, E.; Tcherkez, G. What is the role of putrescine accumulated under potassium deficiency? Plant. Cell Environ. 2020, 43, 1331-1347. [CrossRef] [PubMed]

19. Alvarez, S.; Naldrett, M.J. Mass spectrometry based untargeted metabolomics for plant systems biology. Emerg. Top. Life Sci. 2021, 5, 189-201. [CrossRef]

20. Zhang, K.; Chen, L.; Wei, M.; Qiao, H.; Zhang, S.; Li, Z.; Fang, Y.; Chen, K. Metabolomic profile combined with transcriptomic analysis reveals the value of UV-C in improving the utilization of waste grape berries. Food Chem. 2021, 363, 130288. [CrossRef] [PubMed]

21. Liu, M.; Feng, M.; Yang, K.; Cao, Y.; Zhang, J.; Xu, J.; Hernández, S.H.; Wei, X.; Fan, M. Transcriptomic and metabolomic analyses reveal antibacterial mechanism of astringent persimmon tannin against Methicillin-resistant Staphylococcus aureus isolated from pork. Food Chem. 2020, 309, 125692. [CrossRef] [PubMed]

22. Jeong, J.; Guerinot, M. Lou Homing in on iron homeostasis in plants. Trends Plant Sci. 2009, 14, 280-285. [CrossRef]

23. Jain, A.; Wilson, G.; Connolly, E. The diverse roles of FRO family metalloreductases in iron and copper homeostasis. Front. Plant Sci. 2014, 5, 100. [CrossRef]

24. Muhammad, I.; Jing, X.; Shalmani, A.; Ali, M.; Yi, S.; Gan, P.; Li, W.; Liu, W.; Chen, K. Comparative In Silico Analysis of Ferric Reduction Oxidase (FRO) Genes Expression Patterns in Response to Abiotic Stresses, Metal and Hormone Applications. Molecules 2018, 23, 1163. [CrossRef]

25. Fan, W.; Lou, H.Q.; Gong, Y.L.; Liu, M.Y.; Wang, Z.Q.; Yang, J.L.; Zheng, S.J. Identification of early Al-responsive genes in rice bean (Vigna umbellata) roots provides new clues to molecular mechanisms of Al toxicity and tolerance. Plant. Cell Environ. 2014, 37, 1586-1597. [CrossRef]

26. Dai, J.; Qiu, W.; Wang, N.; Nakanishi, H.; Zuo, Y. Comparative transcriptomic analysis of the roots of intercropped peanut and maize reveals novel insights into peanut iron nutrition. Plant Physiol. Biochem. 2018, 127, 516-524. [CrossRef]

27. Zhang, J.; Liu, B.; Li, M.; Feng, D.; Jin, H.; Wang, P.; Liu, J.; Xiong, F.; Wang, J.; Wang, H. The bHLH transcription factor bHLH104 interacts with IAA-LEUCINE RESISTANT3 and modulates iron homeostasis in Arabidopsis. Plant Cell 2015, 27, 787-805. [CrossRef]

28. Wang, P.; Yang, C.; Chen, H.; Luo, L.; Leng, Q.; Li, S.; Han, Z.; Li, X.; Song, C.; Zhang, X.; et al. Exploring transcription factors reveals crucial members and regulatory networks involved in different abiotic stresses in Brassica napus L. BMC Plant Biol. 2018, 18, 202. [CrossRef]

29. Kabir, A.H.; Akther, M.S.; Skalicky, M.; Das, U.; Gohari, G.; Brestic, M.; Hossain, M.M. Downregulation of Zn-transporters along with Fe and redox imbalance causes growth and photosynthetic disturbance in Zn-deficient tomato. Sci. Rep. 2021, 11, 6040. [CrossRef]

30. Kerry, R.G.; Mahapatra, G.P.; Patra, S.; Sahoo, S.L.; Pradhan, C.; Padhi, B.K.; Rout, J.R. Proteomic and genomic responses of plants to nutritional stress. BioMetals 2018, 31, 161-187. [CrossRef]

31. Zeng, J.; He, X.; Quan, X.; Cai, S.; Han, Y.; Nadira, U.A.; Zhang, G. Identification of the proteins associated with low potassium tolerance in cultivated and Tibetan wild barley. J. Proteom. 2015, 126, 1-11. [CrossRef]

32. Yang, Q.; Liu, Y.; Zeng, Q. Overexpression of three orthologous glutathione S-transferases from Populus increased salt and drought resistance in Arabidopsis. Biochem. Syst. Ecol. 2019, 83, 57-61. [CrossRef]

33. Forde, B.G.; Lea, P.J. Glutamate in plants: Metabolism, regulation, and signalling. J. Exp. Bot. 2007, 58, 2339-2358. [CrossRef]

34. Wang, W.; Wang, J.; Wei, Q.; Li, B.; Zhong, X.; Hu, T.; Hu, H.; Bao, C. Transcriptome-Wide Identification and Characterization of Circular RNAs in Leaves of Chinese Cabbage (Brassica rapa L. ssp. pekinensis) in Response to Calcium Deficiency-Induced Tip-burn. Sci. Rep. 2019, 9, 14544. [CrossRef]

35. Dossa, K.; Li, D.; Wang, L.; Zheng, X.; Liu, A.; Yu, J.; Wei, X.; Zhou, R.; Fonceka, D.; Diouf, D.; et al. Transcriptomic, biochemical and physio-anatomical investigations shed more light on responses to drought stress in two contrasting sesame genotypes. Sci. Rep. 2017, 7, 8755. [CrossRef]

36. Rodriguez, P.L. Protein phosphatase 2C (PP2C) function in higher plants. Plant Mol. Biol. 1998, 38, 919-927. [CrossRef]

37. Singh, A.; Yadav, A.K.; Kaur, K.; Sanyal, S.K.; Jha, S.K.; Fernandes, J.L.; Sharma, P.; Tokas, I.; Pandey, A.; Luan, S.; et al. A protein phosphatase 2C, AP2C1, interacts with and negatively regulates the function of CIPK9 under potassium-deficient conditions in Arabidopsis. J. Exp. Bot. 2018, 69, 4003-4015. [CrossRef]

38. Tiwari, J.K.; Buckseth, T.; Zinta, R.; Saraswati, A.; Singh, R.K.; Rawat, S.; Dua, V.K.; Chakrabarti, S.K. Transcriptome analysis of potato shoots, roots and stolons under nitrogen stress. Sci. Rep. 2020, 10, 1152. [CrossRef]

39. Yu, J.; Ge, H.; Wang, X.; Tang, R.; Wang, Y.; Zhao, F.; Lan, W.; Luan, S.; Yang, L. Overexpression of Pyrabactin Resistance-Like Abscisic Acid Receptors Enhances Drought, Osmotic, and Cold Tolerance in Transgenic Poplars. Front. Plant Sci. $2017,8,1752$. [CrossRef]

40. Arrivault, S.; Senger, T.; Krämer, U. The Arabidopsis metal tolerance protein AtMTP3 maintains metal homeostasis by mediating Zn exclusion from the shoot under Fe deficiency and Zn oversupply. Plant J. 2006, 46, 861-879. [CrossRef]

41. Vert, G.; Grotz, N.; Dédaldéchamp, F.; Gaymard, F.; Guerinot, M.L.; Briat, J.-F.; Curie, C. IRT1, an Arabidopsis Transporter Essential for Iron Uptake from the Soil and for Plant Growth. Plant Cell 2002, 14, 1223-1233. [CrossRef] 
42. Eprintsev, A.T.; Selivanova, N.V.; Igamberdiev, A.U. Enzymatic Conversions of Glutamate and $\gamma$-Aminobutyric Acid as Indicators of Plant Stress Response. In Nitrogen Metabolism in Plants; Gupta, K.J., Ed.; Springer: New York, NY, USA, 2020; Volume 2057, pp. 71-78, ISBN 9781493997909.

43. Shen, C.; Yang, Y.; Liu, K.; Zhang, L.; Guo, H.; Sun, T.; Wang, H. Involvement of endogenous salicylic acid in iron-deficiency responses in Arabidopsis. J. Exp. Bot. 2016, 67, 4179-4193. [CrossRef]

44. Urbanczyk-Wochniak, E.; Fernie, A.R. Metabolic profiling reveals altered nitrogen nutrient regimes have diverse effects on the metabolism of hydroponically-grown tomato (Solanum lycopersicum) plants. J. Exp. Bot. 2005, 56, 309-321. [CrossRef]

45. Liu, L.; Lin, L. Effect of Heat Stress on Sargassum fusiforme Leaf Metabolome. J. Plant Biol. 2020, 63, 229-241. [CrossRef]

46. Popp, M.; Kinzel, H. Changes in the Organic Acid Content of some Cultivated Plants Induced by Mineral Ion Deficiency. J. Exp. Bot. 1981, 32, 1-8. [CrossRef]

47. Yoneyama, T. Iron delivery to the growing leaves associated with leaf chlorosis in mugineic acid family phytosiderophoresgenerating graminaceous crops. Soil Sci. Plant Nutr. 2021, 67, 415-426. [CrossRef]

48. Almeida-Silva, F.; Venancio, T.M. Pathogenesis-related protein 1 (PR-1) genes in soybean: Genome-wide identification, structural analysis and expression profiling under multiple biotic and abiotic stresses. bioRxiv 2021, 809, 146013. [CrossRef]

49. Schwarz, B.; Bauer, P. FIT, a regulatory hub for iron deficiency and stress signaling in roots, and FIT-dependent and -independent gene signatures. J. Exp. Bot. 2020, 71, 1694-1705. [CrossRef]

50. Toprak Aktas, E.; Yildiz, H. Effects of electroplasmolysis treatment on chlorophyll and carotenoid extraction yield from spinach and tomato. J. Food Eng. 2011, 106, 339-346. [CrossRef]

51. Cao, J.; Li, F.; Li, Y.; Chen, H.; Liao, X.; Zhang, Y. Hydrophobic interaction driving the binding of soybean protein isolate and chlorophyll: Improvements to the thermal stability of chlorophyll. Food Hydrocoll. 2021, 113, 106465. [CrossRef] 